\title{
Gambaran Metode Amenorea Laktasi dan Cara Pemberian Asi Eksklusif di Desa Cipacing Kecamatan Jatinangor
}

\author{
Risye Nuroctaviani Lausi ${ }^{1}$, Ari Indra Susanti ${ }^{2}$, Puspa Sari², Sri Astuti ${ }^{2}$ \\ ${ }^{1}$ Program Diploma Kebidanan, Fakultas Kedokteran Universitas Padjadjaran \\ ${ }^{2}$ Departemen Ilmu Kesehatan Masyarakat, Fakultas Kedokteran Universitas Padjadjaran
}

\begin{abstract}
Abstrak
Program Keluarga Berencana Nasional di Indonesia melaksanakan Program Making Pregnancy Safer, salah satu kuncinya yaitu setiap kehamilan merupakan kehamilan yang diinginkan. Program Keluarga Berencana merupakan salah satu pelayanan kesehatan yang bersifat preventif. Pada pemberian ASI Eksklusif dapat menjadi kontrasepsi sementara yang cukup efektif selama klien belum mendapatkan haid dan waktunya kurang dari enam bulan pasca bersalin. Keefektifannya dapat mencapai 98\%. Tujuan penelitian untuk mengetahui gambaran Metode Amenorea Laktasi dan cara pemberian ASI Eksklusif di Desa Cipacing Kecamatan Jatinangor. Metode penelitian ini menggunakan metode dekskriptif dengan pendekatan cross sectional. Populasi dalam penelitian ini adalah ibu-ibu yang mempunyai anak usia 6-12 bulan yang menyusui ASI Eksklusif dilakukan pada tanggal 22-07-2016 s.d 28-06-2016 di Desa Cipacing. Teknik pengambilan menggunakan total sampling dengan jumlah sampel 66 responden dengan data primer. Hasil penelitian ini didapatkan bahwa gambaran pada ibu yang memberikan ASI eksklusif tidak menggunakan kontrasepsi sebanyak 40,9\%, cara pemberian ASI secara on demand $90,9 \%$ dan kembalinya menstruasi $\geq 6$ bulan sebesar $53,0 \%$. Simpulan penelitian ini, bahwa sebagian besar ibu yang memberikan ASI Eksklusif sudah menggunakan KB dengan Metode Amenorea Laktasi dan kembalinya menstruasi pada ibu yang menggunakan KB Metode Amenorea Laktasi lebih dari enam bulan.
\end{abstract}

Kata Kunci : ASI Eksklusif, Kontrasepsi, Metode Amenorea Laktasi.

\section{The Description of Lactational Amenorrhoea Method of Exclusive Breastfeeding in the Village of Cipacing Jatinangor District}

\begin{abstract}
National Family Planning Program in Indonesia implements Making Pregnancy Safer program, which one of the features is that every pregnancy is wanted pregnancy. Family Planning Program is health service which is preventive in nature. Exclusive breastfeeding can act as effective temporary contraception before the client has menstruation within less than six month after delivery. The effectiveness is $98 \%$. This study was intended to describe lactational amenorrhea method and exclusive breastfeeding at Cipacing, Jatinangor district. Method used in this study was descriptive with crosssectional approach. The population was women with 6-12 month old children and have exclusive breastfeeding between July 22th of 2016 to June 28 th of 2016 at Cipacing. Sampling technique was total sampling with number of samples was 66 respondents with primary data. From result of the study, showed that the description of mother who gave exlusive breastfeeding it was obtained that women not using contraception were 40.9\%, on-demand exclusive breastfeeding were $90.9 \%$, and return of menstruation after 6 months were $53.0 \%$. It can be concluded from this study that majority of women with exclusive breastfeeding have been using lactational amenorrhea method of contraception, and return of menstruation in women with lactational amenorrhea method of contraception is more than 6 months.
\end{abstract}

Keywords : Contraception, Exclusive Breastfeeding, Lactational Amenorrhea Method.

Korespondensi:

Risye Nuroctaviani Lausi

Program Studi Diploma Kebidanan, Fakultas Kedokteran Universitas Padjadjaran

Jl. Bandung - Sumedang KM. 21 Jatinangor

Mobile : 086282295480560

Email : lausirisye04@gmail.com 


\section{Pendahuluan}

Paradigma program Keluarga Berencana Nasional telah diubah visinya dari mewujudkan Norma Keluarga Kecil Bahagia Sejahtera atau NKKBS menjadi visi untuk mewujudkan "Keluarga Berkualitas tahun 2015". Keluarga yang berkualitas adalah keluarga yang sejahtera, sehat, mandiri, memiliki jumlah anak yang ideal, berwawasan ke depan, bertanggung jawab, harmonis, dan bertaqwa kepada Tuhan Yang Maha Esa. Misi paradigma baru program Keluarga Berencana ini, sangat menekankan pada pentingnya upaya menghormati hak-hak reproduksi sebagai upaya dalam meningkatkan kualitas keluarga. ${ }^{1,2}$

Masalah utama yang sedang dihadapi negara-negara yang sedang berkembang termasuk Indonesia adalah masih tingginya laju pertumbuhan penduduk. Keadaan penduduk yang demikian telah mempersulit usaha peningkatan dan pemerataan kesejahteraan rakyat. Semakin tinggi pertumbuhan penduduk semakin besar usaha yang diperlukan untuk mempertahankan tingkat tertentu untuk kesejahteraan rakyat. ${ }^{1}$

Alat kontrasepsi sederhana yaitu dengan memanfaatkan masa menyusui yang disebut dengan metode Amenorea Laktasi. Menyusui Eksklusif merupakan suatu metode kontrasepsi sementara yang cukup efektif, selama klien belum mendapat haid dan waktunya kurang dari enam bulan pasca persalinan. Efektifnya dapat mencapai 98\%. Metode Amenorea Laktasi efektif bila menyusui lebih dari delapan kali sehari dan bayi mendapat cukup asupan per laktasi. ${ }^{2}$

Untuk menggunakan Metode Amenorea Laktasi ini diperlukan pengeluaran ASI yang dipengaruhi hormon oksitosin haruslah lancar, yang menurut penelitian yang dilakukan oleh Patricio Valdes Garcia dan Camila Mella sebesar 75\% lancarnya pengeluaran ASI dipengaruhi oleh kondisi psikis ibu itu sendiri, metode Amenorea Laktasi kemungkinan digunakan di beberapa negara berkembang jauh sebelum penelitian mengkonfirmasi bahwa kehamilan jarang terjadi selama 6 bulan pertama setelah melahirkan sesuai dengan penelitian Okoli Uchena diantara wanita menyusui dan wanita yang memberi ASI ditambah susu botol. Ovulasi dapat dihambat oleh kadar prolaktin yang tinggi. Ringkasan 13 penelitian dari 8 negara telah memunculkan kesimpulan yang dikenal sebagai "Pernyataan Konsensus Bellagio", bahwa pemberian ASI mencegah kehamilan $>98 \%$ selama 6 bulan pertama setelah melahirkan bila ibu menyusui atau memberi ASI dan belum pernah mengalami perdarahan pervaginam setelah hari ke-56 pascapartum. ${ }^{7,8}$ Metode Amenorea Laktasi di
Indonesia pencapaiannya masih rendah. Hal ini diukur dari tingkat pencapaian pemberian ASI Eksklusif yang masih rendah. Pemberian ASI eksklusif di Indonesia telah ditetapkan dalam undang-undang oleh pemerintah tetapi menurut hasil Survei Demografi dan Kesehatan Indonesia (SDKI) 2007 menunjukkan cakupan ASI eksklusif bayi 0-6 bulan sebesar 32\% dan menunjukkan kenaikan menjadi $42 \%$ pada tahun 2012. ${ }^{9} \quad$ Penggunaan Metode Amenorea Laktasi di dukung dengan pemberian ASI Eksklusif. Semakin sering pemberian ASI dengan frekuensi \pm 10 -12 kali per hari akan memberikan keuntungan sebagai kontrasepsi salah salah satunya. Keuntungan metode amenorea laktasi meliputi keuntungan kontrasepsi yang segera efektif, tidak mengganggu senggama, tidak ada efek samping secara sistematis, tidak perlu pengawasan medis, serta tidak perlu obat atau alat dan tanpa biaya. ${ }^{10}$

Pada tahun 2015 telah dilakukan hasil Survey Mawas Diri (SMD) di Desa Cipacing Kecamatan Jatinangor bahwa terdapat ibu yang baru melahirkan satu tahun terakhir mengalami hamil kembali sebanyak 6 orang dari jumlah ibu melahirkan dalam satu tahun 235 orang. Cakupan ASI Eksklusif di Desa Cipacing kecamatan Jatinangor sebanyak 47 orang dari 104 orang yaitu $45,19 \%$ dan ibu yang memakai alat kontrasepsi alami sebanyak 38 orang.

Tujuan penelitian ini untuk mengetahui gambaran Metode Amenorea Laktasi dan cara pemberian ASI Eksklusif di Desa Cipacing Kecamatan Jatinangor.

\section{Metode}

Penelitian ini menggunakan metode penelitian deskriptif dengan pendekatan secara cross sectional. Populasi dalam penelitian ini adalah ibu-ibu yang mempunyai anak usia 6-12 bulan yang menyusui ASI Eksklusif yang bertempat tinggal di Desa Cipacing Kecamatan Jatinangor berjumlah 66 bayi dengan responden ibu bayi. Kriteria inklusi dalam penelitian ini adalah Ibu yang tidak menggunakan KB selama memberikan ASI Eksklusif. Teknik pengambilan sampel yang digunakan adalah total sampling, dengan sampel 66 responden yang di dapat. Variabel yang digunakan adalah variabel independen yaitu metode amenorrhea laktasi dan variabel dependen yaitu cara pemberian ASI karena hal ini mempengaruhi variabel lainnya. Pengambilan data dilakukan pada tanggal 22-07-2016 s.d 2807-2016 di Desa Cipacing. Proses pengambilan dan pengumpulan data dalam penelitian ini diperoleh dari data primer. Pengumpulan data 
primer diperoleh langsung dari responden dengan menyebarkan kuesioner yang dibuat peneliti dan diisi oleh ibu-ibu yang mempunyai anak usia 6-12 bulan yang menyusui ASI Eksklusif. Analisis univariat menggunakan distribusi frekuensi untuk variabel tunggal yang dianggap terkait dengan penelitian. Analisis univariat dalam penelitian ini dilakukan untuk mengetahui dan mendapatkan hasil terhadap Metode Amenorea Laktasi dan cara pemberian ASI Eksklusif di Desa Cipacing Kecamatan Jatinangor.

Pada penelitian ini sudah mendapatkan ijin penelitian dari komite-etik FK UNPAD dengan No. 0716090912.

\section{Hasil}

Berdasarkan tabel 1 dapat diketahui dari 27 orang ibu yang memberikan ASI Eksklusif menggunakan KB MAL bahwa semua ibu memberikan ASI Eksklusif secara on demand yaitu 27 orang $(100 \%)$.

Tabel 1 Tabulasi Silang Antara Penggunaan KB MAL dengan Cara Pemberian ASI

\begin{tabular}{|c|c|c|c|c|c|c|}
\hline \multirow{3}{*}{$\begin{array}{c}\text { Penggunaan } \\
\text { KB MAL }\end{array}$} & \multicolumn{4}{|c|}{ Cara pemberian ASI } & \multirow{2}{*}{\multicolumn{2}{|c|}{ Total }} \\
\hline & \multicolumn{2}{|c|}{ Botol } & \multicolumn{2}{|c|}{ on demand } & & \\
\hline & f & $\%$ & $\mathbf{f}$ & $\%$ & f & $\%$ \\
\hline Bukan MAL & 6 & 15.4 & 33 & 84.6 & 39 & 59.1 \\
\hline MAL & 0 & 0.0 & 27 & 100.0 & 27 & 40.9 \\
\hline
\end{tabular}

dari tabel 2 dapat diketahui dari 27 orang ibu yang memberikan ASI Eksklusif menggunakan KB MAL bahwa sebanyak 26 orang (96.3\%) ibu kembali menstruasi $>6$ bulan. Sedangkan dari 39 orang ibu yang memberikan ASI Eksklusif menggunakan KB bukan MAL bahwa sebanyak 30 orang $(76.9 \%)$ ibu kembali menstruasi $<6$ bulan.

Tabel 2 Tabulasi Silang Antara Penggunaan KB MAL dengan Kembalinya Menstruasi

\begin{tabular}{|c|c|c|c|c|c|c|}
\hline \multirow{3}{*}{$\begin{array}{l}\text { Penggunaan } \\
\text { KB MAL }\end{array}$} & \multicolumn{4}{|c|}{$\begin{array}{c}\text { K e } \\
\text { menstruasi } \\
\end{array}$} & \multirow{2}{*}{\multicolumn{2}{|c|}{ Total }} \\
\hline & \multicolumn{2}{|c|}{$<6$ bulan } & \multicolumn{2}{|c|}{$>6$ bulan } & & \\
\hline & f & $\%$ & f & $\%$ & f & $\%$ \\
\hline Bukan MAL & 30 & 76.9 & 9 & 23.1 & 39 & 59.1 \\
\hline MAL & 1 & 3.7 & 26 & 96.3 & 27 & 40.9 \\
\hline
\end{tabular}

Berdasarkan tabel 3 dapat diketahui dari 6 orang ibu yang memberikan ASI Eksklusif dengan botol bahwa semua ibu kembali menstruasi $<6$ bulan yaitu 6 orang (100\%). Sedangkan dari 60 orang ibu yang memberikan ASI Eksklusif secara on demand bahwa sebanyak 35 orang (58.3\%) ibu menstruasi $>6$ bulan

Tabel 3 Tabulasi SilangAntara Cara Pemberian ASI dengan Kembalinya Menstruasi

\begin{tabular}{|c|c|c|c|c|c|c|}
\hline \multirow{3}{*}{$\begin{array}{l}\text { Pemberian } \\
\text { ASI }\end{array}$} & \multicolumn{4}{|c|}{ K e m b a l i n y a } & \multirow{2}{*}{\multicolumn{2}{|c|}{ Total }} \\
\hline & \multicolumn{2}{|c|}{$<6$ bulan } & \multicolumn{2}{|c|}{$>6$ bulan } & & \\
\hline & f & $\%$ & f & $\%$ & f & $\%$ \\
\hline Botol & 6 & 100.0 & 0 & 0.0 & 6 & 9.1 \\
\hline on demand & 25 & 41.7 & 35 & 58.3 & 60 & 90.9 \\
\hline
\end{tabular}

\section{Pembahasan}

Berdasarkan tabel 1 mengenai penggunaan KB MAL dengan pemberian ASI dapat diketahui dari 27 orang yang memberikan ASI Eksklusif menggunakan KB MAL keseluruhan ibu memberikan ASI Eksklusif secara on demand yaitu sebanyak $100 \%$. Pemberian ASI sangat memengaruhi dimana pemberian ASI secara ondemand yaitu menyusui kapanpun bayi meminta. Hal ini dapat mengendalikan emosi dan pikiran agar tenang karena frekuensi menyusui yang tidak menentu. Menambah panjang kembalinya kesuburan pasca persalinan sehingga menunda kehamilan berikutnya atau dapat berperan juga sebagai KB alami. Salah satu kendala menyusui eksklusif yaitu adanya peningkatan pekerja perempuan. Hal ini dapat menyebabkan kesulitan, masalah dan kegagalan dalam menyusui, sedangkan memberikan ASI hak semua ibu, termasuk ibu bekerja. Menyusui yang dijadwalkan seperti halnya menggunakan botol akan berakibat kurang baik, karena isapan bayi sangat berpengaruh pada rangsangan produksi ASI selanjutnya. Pada ibu bekerja dianjurkan menyusui lebih sering pada malam hari karena akan memicu produksi ASI, sehingga nanti tidak akan timbul masalah menyusui. , $^{1,41}$

Menurut rekomendasi WHO bahwaASI adalah hak anak dan merupakan makanan terbaik bayi sejak lahir sampai anak usia 2 tahun. Peraturan Pemerintah yang dikuatkan oleh kebijakan yang mendukung pemberian ASI untuk melindungi, serta memberikan yang terbaik agar anak tumbuh dan berkembang secara optimal, sehat, dan cerdas. Diantara sekian banyak manfaat ASI diantaranya adalah memberi gizi yang berkualitas tinggi untuk pertumbuhan optimum, sebagai cairan yang dibutuhkan bayi karena mengandung kolostrum yang amat penting untuk bayi baru lahir karena sangat mempengaruhi pertumbuhan, pencernaan, dan perlindungan kesehatan bayi. ${ }^{18}$

Pada pemberian ASI ada faktor- faktor yang 
memengaruhi pemberian ASI seperti halnya umur, pendidikan, pekerjaan dan paritas. Pada penelitian ini terlihat tingkat pengetahuan yang dimiliki serta peran lingkungan yang memengaruhi pemberian ASI. Alasan lain yang menyebabkan ibu tidak memberikan ASI yaitu ASI ibu sedikit sehingga ibu khawatir bayi tidak mendapatkan asupan yang mencukupi. Alasan lain yaitu ibu bekerja, keluarga yang membantu merawat bayinya sehingga pada saat bayi sedang menangis dan rewel banyak keluarga atau teman yang menyarankan ibu untuk memberikan makan selain ASI. ${ }^{15}$

Berdasarkan UUD pasal 27 ayat 2, bahwa tiap-tiap warga negara berhak atas pekerjaan dan penghidupan yang layak bagi kemanusiaan, yang maknanya adalah seorang ibu bekerja tetap mendapatkan hak bekerja yang layak dalam artian luas, termasuk menyusui anaknya karena menyusui adalah hak asasi manusia, serta hak asasi anak untuk hidup layak. Namun, dalam kenyataannya terdapat kendala untuk menyusui eksklusif, sehingga pemberian ASI eksklusif masih rendah di beberapa daerah di Indonesia. Pada hasil penelitian yang dilakukan oleh Okolie Uchenna mengatakan bahwa keberhasilan seseorang menyusui tergantung kepada setiap individu dan lingkungan yang memengaruhi ibu dalam pemberian ASI. Banyak hal yang menjadi kendala dalam pemberian ASI Ekslusif dan terlihat juga pada penelitian ini bahwa hambatanhambatan dalam pemberian ASI yang sangat memengaruhi adalah faktor lingkungan. ${ }^{719,23}$

Berdasarkan tabel 2 mengenai penggunaan KB MAL dengan kembalinya menstruasi dapat diketahui dari 27 orang ibu yang menggunakan ASI Eksklusif menggunakan KB MAL bahwa sebanyak 96,3\% ibu kembali menstruasi $>6$ bulan. Kembalinya siklus menstruasi setelah persalinan merupakan salah satu tanda kembalinya kemampuan reproduksi. Pada ibu menyusui secara eksklusif dapat membantu terhambatnya ovulasi oleh hormon prolaktin yang tinggi sehingga ibu tidak mengalami menstruasi untuk beberapa waktu. Oleh karena itu menyusui secara eksklusif terdapat beberapa manfaat terpenting bagi ibu salah satunya sebagai kontrasepsi alamiah. Hai ini sering kali tidak diketahui oleh para ibu menyusui dan dari hasil penelitian terlihat bahwa di tabel $1 \mathrm{ibu}$ yang menyusui ASI Eksklusif dengan penggunaan KB MAL yaitu sebesar $40,9 \%$ masih terlihat rendah. Terdapat beberapa faktor yang mempengaruhi hal tersebut seperti hal nya pengetahuan yang kurang terhadap informasi mengenai hal tersebut. Pada hasil penelitian di dapat 27 orang yang tidak menggunakan KB pada saat menyusui. Dari 27 orang yang mengetahui metode amenore laktasi sebanyak 17 orang hal tersebut dipengaruhi oleh paritas dan pengetahuan ibu. Berdasarkan hasil penelitian diketahui bahwa ibu yang berhasil menyusui sampai enam bulan mendapatkan dukungan yang baik dari petugas kesehatan berupa pemberian informasi tentang ASI Eksklusif. Ibu yang mendapatkan dukungan dari keluarga memberikan ASI lebih lama bila dibandingkan yang tidak mendapatkan dukungan dari keluarga. ${ }^{24,25}$

Berdasarkan tabel 3 mengenai cara pemberian ASI dengan kembalinya menstruasi didapat bahwa 60 orang ibu yang memberikan ASI Eksklusif secara on demand sebanyak 58,3\% kembali menstruasi $>6$ bulan. Hal ini dapat dipengaruhi oleh menyusui eksklusif karena dengan menyusui konsentrasi prolaktin tetap meninggi selama pengisapan sering terjadi dan pada setiap kali menyusu terjadi peningkatan sekresi prolaktin secara akut. Pada dasarnya hormone FSH (Follicle Stimulating Hormone) kembali ke normal dalam beberapa minggu pascapartum. Namun konsentrasi LH (Luteinizing Hormone) dalam darah tetap tertekan sepanjang periode menyusui. Pada saat menyusui konsentrasi prolaktin menjadi inhibitor untuk keluarnya LH, sehingga pulsasi normal pelepasan LH mengalami gangguan dan inilah yang menjadi dasar penyebab terjadinya penekanan fungsi normal ovarium. ${ }^{7,9,14}$

Oleh karena itu dari hasil penelitian terlihat bahwa ibu yang memberikan ASI selama 6 bulan penuh atau menyusui eksklusif dan tidak memakai alat kontrasepsi selama memberikan ASI eksklusif dan kembali menstruasinya $\geq 6$ bulan. Pada penelitian sebelumnya yang dilakukan oleh Gustri dan Sri Handayani keadaan ini dapat dikaitkan dengan Metode Amenorea Laktasi (MAL) dan dapat dikatakan sebagai metode keluarga berencana alamiah (KBA) apabila dikombinasikan dengan kontrasepsi lain. Menyusui eksklusif merupakan suatu metode kontrasepsi sementara cukup efektif, selama ibu belum mendapat haid dan waktunya kurang dari enam bulan pasca persalinan. Salah satu tanda belum kembalinya kesuburan seorang wanita adalah tidak datangnya menstruasi setelah melahirkan. Berapa lama seorang wanita kembali subur tergantung pada pola menyusui bayinya dan kecenderungan tubuhnya sendiri. Keefektifan sebagai kontrasepsi menurun seiring dengan lamanya menyusui. ${ }^{17}$

Penelitian ini telah diusahakan dan dilakukan sesuai dengan pedoman penelitian, namun demikian masih memiliki keterbatasan. Penelitian ini merupakan penelitian yang menggunakan data primer atau pertanyaan yang sesuai dengan pengalaman ibu apabila data itu dibutuhkan. Sehingga variabel-variabel yang 
diteliti disesuaikan pada variabel yang ada pada data. Selain itu, penelitian ini juga menggunakan desain cross sectional, yaitu mengkaji masalah pada saat penelitian berlangsung dimana variabel independen serta variabel dependen diamati pada waktu bersamaan.

Dari hasil penelitian dapat diambil kesimpulan bahwa ibu yang menggunakan alat kontrasepsi sederhana yaitu Metode Amenore Laktasi (MAL) masih sangat rendah dipengaruhi juga oleh pemberian ASI Eksklusif yang belum optimal. Sebagian besar ibu yang memberikan ASI Eksklusif dengan penggunaan KB MAL dan kembalinya menstruasi pada ibu yang menggunakan KB MAL lebih dari enam bulan.

Tenaga kesehatan terutama bidan lebih meningkatkan penyuluhan mengenai ASI Eksklusif dan manfaat ASI Eksklusif serta mengenai metode KB alamiah kepada ibu hamil, ibu nifas serta ibu yang memiliki bayi usia $0-12$ bulan, karena manfaatnya tidak hanya dirasakan oleh bayi tetapi dirasakan juga oleh ibu. Maka masih perlu ditingkatkan lagi pemberian KIE melalui bidan, dokter, perawat, kader posyandu mengenai ASI Eksklusif.

\section{Daftar Pustaka}

1. Saifuddin. Buku Panduan Praktis Pelayanan Kontrasepsi. Jakarta : PT. Bina Pustaka Sarwono Prawirohardjo.2010. hlm 59-62

2. Jannah, Ahadyah Miftahul. Tingkat Pengetahuan Ibu Nifas Tentang Kontrasepsi Metode Amenorea Laktasi Di RSUD DR. Moewardi. 2014. Surakarta.

3. Pusat data dan informasi. Situasi dan analisis keluarga berencana (KB). Jakarta: Kementerian kesehatan RI; Di unduh tanggal 11 Agustus 2016.

4. BKKBN. Kumpulan Data Program Keluarga Berencana Nasional. Jakarta: SDKI; 2013. Di unduh tanggal 11 Agustus 2016.

5. Laporan peserta $\mathrm{KB}$ aktif provinsi Jawa Barat. Bandung: BKKBN; 2013. Di unduh pada tanggal 11 Agustus 2016.

6. Rakerda program kependudukan keluarga berencana dan pembangunan keluarga kabupaten Sumedang. Sumedang: BPMPDKBPP Kabupaten Sumedang; 2015.

7. Uchenna O. Problems encountered by breastfeeding mothers in their practice of exlusive breast feeding in tertiary hospitals in Enugu state, South-east Nigeria. 2012 diakses pada tanggal 22-11-2015 pukul 16.51 wib.

8. Garcia, Patricio Valdes, Mella Camila. Analysis Of Factors Involved In Lactational
Amenorrhea. 2013 diakses pada tanggal 2211-2015 pukul 16.30 wib

9. Situasi dan analisis ASI eksklusif. Jakarta: Pusat data dan informasi kementerian kesehatan republik indonesia; 2014.

10. Astuti S, Judistiani T, Rahmiati L, Susanti A. Asuhan kebidanan nifas dan menyusui. Jakarta: Erlangga; 2015. hlm 69-76

11. Varney H. Buku ajar asuhan kebidanan. Jakarta: EGC; 2007. hlm 245-249

12. Suparmi. Pengaruh ASI eksklusif terhadap amenorrhea laktasi di Indonesia. Fakultas Kesehatan Masyarakat.Universitas Indonesia. 2010 diakses 2-12-2015 pukul 16.15 wib

13. Yanti, Gustri. Handayani, Sri. 2014. Hubungan Pengetahuan Dan Sikap Dengan Pelaksanaan Metode Amenore Laktasi (MAL) Pada Ibu Nifas Di Wilayah Kerja Puskesmas Kecamatan Sukoharjo Lampung. Vol.05 No. 02 Juli 2014.

14. Fraser D. Myles buku ajar bidan. Jakarta: EGC; 2009. hlm 349-354

15. Afifi M. Lactational amenorrhoea method for family planning and women empowerment in egypt. 2007. Diakses pada tanggal 03-122015 pukul 12.35 wib.

16. Sipsma, Heather L. Elizabeth H. Bradley. Chen, Peggy G. Lactational Amenorrhea Method as a Contraceptive Strategy in Niger. 2012 diakses pada tanggal 13-02-2016 pukul 06.05 wib.

17. Ida. Faktor-faktor yang berhubungan dengan Pemberian ASI Eksklusif 6 Bulan di Wilayah Kerja Puskesmas Kemiri Muka Kota Depok Tahun 2011. Universitas Indonesia diakses pada tanggal 11-12-2015 pukul 08.55 wib

18. Setyawati, Kristin. Hubungan Pengetahuan Ibu Menyusui Tentang ASI Eksklusif Di Desa Tajuk Kecamatan Getasan Kabupaten Semarang. 2012. Semarang

19. Pubudu de Silva. Sri Jayewardenepura Breastfeeding Study: Maternal and infant outcomes in relation to the duration of breast feeding. Sri Lanka. 2009; 31: 88-96

20. Tamara $H$, Melina M, Jacqueline G, Damian J, Babil Stray P, dkk. Exclusive Breastfeeding up to Six Months is Very Rare in Tanzania: A Cohort Study of Infant Feeding Practices in Kilimanjaro Area.Tanzania. 2015; 3(2): 251258

21. Utami, Hajijah Septia. Perilaku Ibu Dalam Praktek Pemberian ASI Eksklusif Di Wilayah Kerja Puskesmas Kecamatan Koba Kabupaten Bangka. Fakultas Kesehatan Masyarakat Universitas Indonesia. Depok. 2012.

22. Fitriani A, Abdullah M, dkk. Hubungan 
Risye Nuroctaviani Lausi : Gambaran Metode Amenorea Laktasi dan Cara Pemberian Asi Eksklusif di Desa Cipacing Kecamatan Jatinangor

Lama Pemberian ASI Ekslusif dengan Lama Amenorhea Laktasi Di Wilayah Kerja Puskesmas Galesong Utara. Makasar. 2013.

23. Oche MO, Umar AS, dkk. Knowledge and practice of exclusive breastfeeding in Kware, Nigeria. African. 2011; 11(3): 518-523

24. Muzayyaroh, Fatimah Listriana. Hubungan
Pemberian ASI Eksklusif dengan Kembalinya Menstruasi Pada Ibu Menyusui di Desa Ngumpul, Jogoroto, Jombang. FIK UNIPDU Jombang. 2014.

25. Lestari Puput. Tingkat Pengetahuan Ibu Nifas Tentang Kontrasepsi MAL Di RSUD Kota Surakarta. Surakarta. 2013. 